\title{
O futuro Mercosul*
}

\author{
Cristiana Campos Mamede Maia' \\ Caroline Debatin Bastos ${ }^{2}$
}

\section{Resumo}

O presente artigo tem por objetivo discutir se o Mercosul conseguirá, após vinte anos de sua existência, desenvolver-se suficientemente para atingir o seu objetivo primeiro, qual seja, o estabelecimento de uma tarifa externa comum e a adoção de uma política comercial comum; a coordenação de políticas macroeconômicas e setoriais entre os Estados Partes, a fim de assegurar condições adequadas de concorrência entre os Estados Partes e o compromisso dos Estados Partes de harmonizar suas legislações, nas áreas pertinentes, para lograr o fortalecimento do processo de integração (MERCOSUL, Tratado de Assunção, Artigo $1^{\circ}$ ), como a elaboração do "Acordo sobre Residência para Estados do Mercosul". Articulado a esse questionamento, o presente artigo discute se as sucessivas crises que atingem a América Latina não influenciarão uma "involução" desse bloco econômico.

Palavras-chave: Mercosul. Blocos econômicos. União Europeia.

\section{0 futuro Mercosul}

Com o fim da Guerra Fria e a consequente ascensão dos Estados Unidos ao status de potência mundial, surgiu a necessidade de uma maior integração internacional por parte dos demais países, como forma de proteger suas economias e adquirir maior potencial competitivo.

\footnotetext{
* Recebido em 28.02.11. Aprovado em 18.04.11.

1 Pós-graduada em Processo Civil (Universidade Cândido Mendes, IAVM 2010); Especialista em Direito Imobiliário; Bacharelanda em Direito (Universidade Cândido Mendes); Bacharel em Desenho Industrial (Universidade da Cidade do Rio de Janeiro, 2006), Orientation to US Law (UC Davis, Califórnia). Email: cristianamaia@gmail.com.

2 Bacharelanda em Direito (Universidade Cândido Mendes). E-mail: cb.debatin@gmail.com.
} 
Nesse diapasão, foi criado o Mercosul, que consiste em um bloco econômico que tem como principal objetivo a livre circulação de mercadorias e o estabelecimento do compromisso, por parte dos países membros, de harmonizar suas legislações para lograr o fortalecimento desse processo de integração. ${ }^{3}$

O processo de integração nada mais é do que a cooperação entre países, que são, via de regra, geograficamente próximos ou possuem algum tipo de afinidade (cultural e/ou comercial), com o fim de mitigar as barreiras econômicas existentes entre eles, viabilizando, dessa forma, a livre circulação de mercadorias, pessoas e capitais e, por conseguinte, aumentar a competitividade desses Estados no cenário internacional.

Com o fenômeno da globalização, torna-se absolutamente necessária a cooperação entre países no âmbito econômico mundial, uma vez que, isolados, não conseguiriam se firmar no atual sistema capitalista.

O Mercosul é composto por Brasil, Argentina, Uruguai e Paraguai, tendo sua origem no Tratado de Assunção, celebrado em 1991. No advento de sua criação, o Tratado possuía primordialmente uma finalidade econômica.

Em 2002, com o "Acordo sobre Residência para Nacionais dos Estados Partes do Mercosul", o tratado ganhou uma maior abrangência, dispondo acerca da

\footnotetext{
3 Artigo $1^{\circ}$ - Os Estados Partes decidem constituir um Mercado Comum, que deverá estar estabelecido a 31 de dezembro de 1994, e que se denominará "Mercado Comum do Sul". (CRISE..., 2008).

Este Mercado Comum implica: a livre circulação de bens serviços e fatores produtivos entre os países, através, entre outros, da eliminação dos direitos alfandegários restrições não tarifárias à circulação de mercado de qualquer outra medida de efeito equivalente. O estabelecimento de uma tarifa externa comum e a adoção de uma política comercial comum em relação a terceiros Estados ou agrupamentos de Estados e a coordenação de posições em foros econômicos comerciais regionais e internacionais. A coordenação de políticas macroeconômicas e setoriais entre os Estados Partes - de comércio exterior, agrícola, industrial, fiscal, monetária, cambial e de capitais, de serviços, alfandegária, de transportes e comunicações e outras que se acordem -, a fim de assegurar condições adequadas de concorrência entre os Estados Partes; e o compromisso dos Estados Partes de harmonizar suas legislações, nas áreas pertinentes, para lograr o fortalecimento do processo de integração.
} 
circulação de pessoas nos países pertencentes ao bloco, demonstrando uma tímida intenção de aprofundar as relações integracionalistas entre os Países Membros.

Tal objetivo secundário pode ser visto, inclusive, na Constituição Brasileira de 1988, conforme está disposto no artigo $4^{\circ}$ em seu parágrafo único, ${ }^{4}$ bem como no próprio Tratado de Assunção em seu artigo $1^{\circ}$, quando trata da intenção dos Países Membros de acelerar um processo de integração entre eles.

Atualmente, o Mercosul encontra-se numa fase de transição, na tímida tentativa de aproximar-se da bem sucedida União Europeia. Porém ainda falta um longo percurso até que tal objetivo se concretize, sendo marcado por diversas crises, sejam estas no âmbito econômico ou político mundial.

Com o advento da última crise econômica, muitos consultores defenderam a ideia de que uma renovação mais radical do Mercosul seria a solução para evitar que os efeitos dessa crise econômica mundial de 2008 o atingissem de uma forma irremediável (CRISE..., 2008), posto a existência de diversas peculiaridades na sua formação.

Deve-se lembrar que a grande diferença econômica entre os Países Membros do Mercosul o enfraquece como bloco integrado, gerando diversos problemas internos como a impossibilidade da adoção de uma moeda única. Um exemplo dessa disparidade é o fato de que o Mercosul possui um PIB de três trilhões de dólares, sendo que $70 \%$ desse valor corresponde ao Brasil. Tal assimetria, por vezes, levou os demais países do bloco a adotarem medidas restritivas ao comércio, como as salvaguardas, a fim de proteger suas economias em relação ao Brasil, medidas estas vetadas pelo Tratado de Assunção por descaracterizarem o fenômeno do bloco econômico.

Tal enfraquecimento é visto especialmente em momentos de crise, como o que assolou o Brasil e a Argentina em 1999, gerando desemprego e recessão, e os

\footnotetext{
4 Art. $4^{\circ}, \S$ único: "A República Federativa do Brasil buscará a integração econômica, política, social e cultural dos povos da América Latina, visando a formação de uma comunidade latino-americana de nações."
} 
países economicamente mais fracos são levados a adotar medidas protecionistas. No caso da crise de 1999, o governo argentino chegou a regulamentar um sistema de salvaguardas que seria também aplicável aos demais países do Mercosul. Tratava-se da Resolução n 911, geradora de uma rápida reação por parte do governo brasileiro, tendo este buscado apoio dos demais países do bloco para suspendê-la.

Outro ponto contundente que merece destaque é a falta de equilíbrio na atuação das relações comerciais dos Estados Membros do Mercosul, onde temos o Brasil e a Argentina muito atuantes, enquanto os demais países possuem intercâmbio comercial bem menor, tornando, dessa forma, certos acordos internos desvantajosos para estes últimos, afastando o bloco de seus objetivos originais como a adoção de uma moeda única e uma maior harmonização entre Países Membros.

Tais problemas, somados à tradicional inércia do Mercosul em relação a mudanças concretas em suas políticas, deixam em dúvida sua capacidade de, um dia, atingir os objetivos aos quais se propôs em sua criação, em especial no que concerne à integração efetiva entre os países da América Latina, como acorreu na União Europeia.

Pode-se dizer que a utopia de uma união interamericana tem origem no processo de formação dos Estados Unidos da América. Com a proximidade geográfica entre os Estados europeus e sua integração, tornou-se possível fomentar o sentimento de identidade europeia. Aquele que antes era português, espanhol ou alemão, apesar de ainda o ser, tornou-se também europeu.

Diferentemente, os países americanos não se permitiram tal adjetivação, tanto pela necessidade de se identificarem com seus próprios países de origem quanto pelo lema estadunidense A América para os americanos. Diante da exportação maciça da cultura estadunidense, o termo americano tornou-se um adjetivo inerente apenas aos de nacionalidade estadunidense. Tal fenômeno incentivou a segregação do Continente Americano em três. Os colonos que saíram da Europa e foram para a América do Norte deram origem ao povo que, ao se revoltar contra o domínio inglês e tornar independentes as treze colônias, intitularam-se americanos, muito se diferenciando da independência dos países da America Latina. 
O processo de independência dos Estados Unidos da América deu-se mediante a chamada Guerra de Independência e, em 1776, este já era um país independente. Entretanto, não seria incorreto afirmar que, antes disso, já se falava em uma cultura americana. Foi justamente isso que possibilitou a união das colônias contra o domínio britânico.

Os países americanos levaram em torno de duzentos anos para conseguirem a total independência política da Europa.

$\mathrm{Na}$ America Latina, pode-se dizer que tal processo foi marcado pela peculiaridade com que cada país conquistou sua independência, sob a névoa do Iluminismo no século XVIII. O Suriname, último país a fazê-lo, só o conseguiu em 1975. No entanto, foi somente após a Revolução Francesa que esse processo de descolonização mostrou-se mais intenso.

Embora a União Europeia tenha sido a inspiradora do Mercosul, existem diferenças profundas entre as duas organizações. Pode-se dizer que o Mercosul encontra-se em um estágio anterior ao da União Europeia, preconizando a instituição de um mercado comum, por meio de uma união aduaneira e da livre circulação dos bens e das pessoas, enquanto a União Europeia preconiza uma união econômica e monetária, além de ter concretizado uma integração econômica e política. Outro ponto que difere esses dois blocos econômicos foram os fatores que levaram à associação. Enquanto na Europa tal associação se deu devido à conjuntura do pós-guerra, no Cone Sul tal se deu devido à necessidade de globalização e interdependência (PEREIRA, 2006, p. 174-176).

Por fim, outro ponto que culminou no sucesso da integração europeia, diferentemente do Mercosul, foi o fato de haver uma menor heteronímia socioeconômica entre os Estados Partes. Tal realidade permitiu uma prosperidade nunca experimentada pelo bloco sul americano que, até o presente momento, enfrenta dificuldades em razão da atual presença dos focos ditatoriais em países como Bolívia e Venezuela, impedindo uma maior integração entre estes países e o Bloco. 
O processo de integração pretendido pelo Mercosul só poderá se concretizar quando os Estados Membros alcançarem uma harmonização da vontade política, cooperação e participação de todos os setores envolvidos, em razão de serem as economias dos Países-Membros economias concorrentes.

Dessa forma, surge a dúvida se essas sucessivas crises que vêm atingindo a America Latina não irão influenciar em uma possível involução do Mercosul, visto que ele está estruturado em um sistema democrático de governo de fraca influência política, e, ao mesmo tempo seus Países Membros estão cercados de formas de governo ditatoriais em seus países vizinhos.

Tal perspectiva, ou a falta dela, cria grande insegurança. Os Estados que compõem a America do Sul veem-se diante da escolha entre um imperialismo brasileiro ou estadunidense.

A inaptidão dos países sul-americanos para a democracia torna-se cada vez mais evidente e uma coexistência como a europeia requer um sentimento de americanismo que, até o momento, inexiste.

Diferente da União Europeia, o Mercosul encontra-se marcado pela diferença cultural e econômica. De um lado, há dois países de proporções continentais enquanto que, do outro, há outros dois pequenos vizinhos, tanto econômica quanto geograficamente (DEL POZO, 2003).

$\mathrm{Na}$ esperança de um futuro para o Mercosul, a integração é um grande desafio, que engloba questões muito mais profundas do que a proximidade geográfica e o idioma. Devem ser observadas as ideologias políticas, as metas econômicas e, acima de tudo, o respeito às diferenças de cada Estado, sem o predomínio de imperialismos protecionistas. 


\title{
The new Mercosul
}

\begin{abstract}
This article aims to discuss if Mercosur will succeed, after twenty years of existence, and if it will grow sufficiently to reach their primary goals: apply a common tax as a common commercial policy, the coordination of macroeconomic and sectoral policies between the States Parties to ensure proper competition between this States Parties, and the commitment of States Parties to harmonize their legislation in order to strengthen the process of integration (MERCOSUR, the Treaty of Asuncion, Article 1th). This article will analyse this subject with the drafting of the Agreement on Residence for the states of Mercosur, and will discuss whether the successive global crises afects the Latin America, and the future Mercosur.
\end{abstract}

Keywords:_Mercosur. Economic blocks. Europe Union.

\section{Referências}

CRISE econômica: renovação MERCOSUL. Disponível em: <http://www. administradores.com.br/informe-se/informativo/crise-economica-renovacaomercosul/14074/>. Acesso em: 14 fev. 2008.

DEL POZO, Carlos Francisco Molina. Integração e ampliação da União Europeia. Curitiba: Juruá, 2003.

BARROSO apela à coordenação entre Estados membros para responder à crise financeira. Jornal Público, Lisboa. Disponível em: <http://economia.publico.pt/ Noticia/barroso-apela-a-coordenacao-entre-estadosmembros-para-responder-acrise-financeira_1345366>. Acesso em: 31 dez. 2010.

MORE, Rodrigo Fernandes. Integração econômica internacional. Jus Navigandi, Teresina, ano 7, n. 59, 1 out. 2002. Disponível em: <http://jus.uol.com.br/revista/ texto/3307/integracao-economica-internacional>. Acesso em: $31 \mathrm{dez} .2010$.

PEREIRA, A. C. P. Direito institucional e material no Mercosul. 2. ed. Rio de Janeiro: Lumens Iuris, 2005. 


\section{Para publicar na revista Universitas}

Relações Internacionais, entre no endereço eletrônico www.publicacoesacademicas.uniceub.br. Observe as normas de publicação, facilitando e agilizando o trabalho de edição. 